\title{
Impact of Spirituality on Well-Being among Old Age People
}

\author{
Razia Saleem ${ }^{1}$, Dr. Kr. Sajid Ali Khan ${ }^{2}$
}

\section{ABSTRACT:}

The present study was planned to find out the impact of Spirituality on Well-being among old age people. Sample of the present study comprised of one hundred old age people (age range 50 to 65). Sample was randomly selected from different areas of Aligarh. The data were collected by Spirituality Attitude Scale (Hussian et al., 2011) and Well-Being Scale (Jagsharanbir Singh and Dr. Asha Gupta, 2001). Simple Linear Regression was applied to examine the Correlation between Spirituality and Well-being as well as Coefficient of Spirituality on Well-being. Whereas, it was found to be $\mathrm{R}=.359$ and $\mathrm{R}$ Square Change was $12 \%$ which represent the contribution (Impact) of predictor variable on Well-being among Old age people. The Correlation was computed between Spirituality and Different dimensions of Well-being i.e. Physical, Mental, Social, Emotional and Spiritual and it was found to be .542, .592, .524, .527 and .451 respectively. Further, Correlation was applied between Overall Well-being and Different dimensions of Spirituality i.e. Sense of Purposeness and Maintenance of Discipline which was found to be .696 and .534 . Well-being is concern for an individual by which he can live a better life on which the happy life of the society is based. In order to be living long an individual should be involve in religious practices throughout his/her life.

Keywords: Spirituality, well-being \& old-age people.

Spirituality plays an important role in the lives of older peoples. Spirituality is one of the most important sources of strength and direction in people's lives. It is a human phenomenon, which exist in almost all persons. The term spirituality generally used to denote certain positive inward qualities and perceptions while avoiding implications of narrow, dogmatic beliefs and obligatory religious observances (wulff, 1996). Spirituality is a unified quality of mind, heart, and soul. It is concerns with individual subjective experiences, sometimes shared with others. Spirituality plays an important role in Indian society across all ages. As one gets older, the role of spirituality becomes more prominent.

The concept of spirituality includes multiple dimensions which may have different meanings and interpretations.

\footnotetext{
${ }^{1}$ Research Scholar, Department of Psychology, Aligarh Muslim University, Aligarh.

${ }^{2}$ Associate Professor, Department of Psychology, Aligarh Muslim University, Aligarh.
} 
Spirituality is usually observed in individuals', families,' and communities' thoughts, behaviors and languages that are assumed to emanate from their intra, inter and transpersonal experiences with spirit (Swinton, 2001). Intrapersonal refers to a connectedness within oneself and focuses on the potential of the self and the resource of inner strength. Interpersonal represents the connectedness with others and environments. Transpersonal refers to a sense of connectedness with God or a 'higher' power other than the self and ordinary resources. (Reed, 1992) Spirituality was defined as a common human experience that forms an integral part of every person's search for meaning and purpose in life, suffering and illness and the outward expression about an intra, inter and transpersonal experience of the individual (Reed, 1992, Tanyi, 2002; Swinton, 2001). Spirituality is a complex and has many dimensions, for example, miller and thorenson (2000) proposed three broad measurement domains; spiritual practices, beliefs, and experiences. Spirituality can be assessed in a variety of ways like clinical interview, spiritual measures in three domains viz., belief, and behaviour experience. The broad goal of assessment understands. Spiritual life means the development of self- consciousness and the cultivation of one's inner resources through personal efforts and personal choice. Spirituality can help people maintain good well-being.it can help them cope with everyday stress and keep them grounded. Spirituality can also help people deal with mental distress and mental illness. Spirituality can be a feeling of being connected to something bigger than yourself and it provide a way of coping an addition to your own mental resilience. It can also help the people make sense of what they are experiencing

Spirituality or beliefs may be described as experiencing a deep sense of meaning and purpose in Life, together with a sense of belonging. It is about acceptance, integration and wholeness. It applies to everyone, including those who do not believe in God or a 'higher being'. For an individual, their spiritual, religious or personal beliefs may be particularly important in times of emotional stress, physical and mental illness, loss and bereavement. People's beliefs and experiences of spiritual or religious matters can change through the course of their lives and may differ from that of their family of origin. Spirituality is a deep feelings and beliefs - both religious and non-religious - and often this involves questions about who we are and why we exist, or the meaning and purpose of life. It involves many factors such as morals and principles, ethics and values, one's connection to others or relationships with them, and a sense of belonging. It has also been described as acceptance of being human and a sense of wholeness, irrespective of intellectual ability. It is believed that when we are spiritually healthy our inner selves can be in harmony with the world around us, even when we are under emotional, mental or physical stress.

Spiritual life can give people strength and impress their well-being. But some people experiences of spirituality may be damaging to their mental health. They may find certain belief systems repressive and their follower's judgmental. King et al (2013) investigated religion, spirituality and mental health: results from a national study of English households they found out that people who have a spirituality understanding of life in the absence of a religious framework are 
vulnerable to mental disorder. Interest in spirituality and aging has increased recently, primarily owing to empirical research overwhelmingly demonstrating the various health benefits of spirituality and religious participation. Studies have also shown that spirituality tends to increase during later adulthood. Interestingly, this trend of increased spiritual growth and religious activities in older age people continues in modern society, despite significant secularization of the society compared with 50 years ago. Spirituality moderates positive relationships with various measures of life satisfaction

Spiritual wellbeing is about our inner life and its relationship with the wider world. It includes our relationship with the environment, our relationships with others and with ourselves. Spiritual wellbeing does not just reflect religious belief although for people of a religious faith it is obviously a central feature. Each person's spirituality is greatly impacted by the community they are a part of and their relationships. To be spiritually well will mean a positive engagement with others, self and our environment. Spirituality moderates positive relationships with various measures of life satisfaction, psychosocial wellbeing, both physical and mental health, and is helpful in the quest for meaning and purpose in life. Understanding an individual's spiritual perspective becomes increasingly important, given the issues of loss, physical illness, disability and mortality that are confronted in old age.

Well-being is an individual's satisfaction with life and with the cultural and intellectual conditions under which he/she lives with goals, expectations and concerns (Diener et al., 1999). Each individual and family makes broad judgments about his or her life as a whole, as well as about domains such as marriage and work. Well-being is a positive outcome that is meaningful for people and for many sectors of society, because it tells us that people perceive that their lives are going well. Good living conditions (e.g., housing, employment) are fundamental to wellbeing. Tracking these conditions is important for public policy. However, many indicators that measure living conditions fail to measure what people think and feel about their lives, such as the quality of their relationships, their positive emotions and resilience, the realization of their potential, or their overall satisfaction with life-i.e., their "well-being. It generally includes global judgments of life satisfaction and feelings ranging from depression to joy. Well-being includes the presence of positive emotions and moods (e.g., contentment, happiness), the absence of negative emotions (e.g., depression, anxiety), satisfaction with life, fulfillment and positive functioning. In simple terms, well-being can be described as judging life positively and feeling good.

Well-being or welfare is a general term for the condition of an individual or group, for example their social, economic, psychological, spiritual or medical state; high well-being means that, in some sense, the individual or group's experience is positive, while low well-being is associated with negative happenings. In economics, the term is used for one or more quantitative measures intended to assess the quality of life of a group, for example, in the capabilities approach and the economics of happiness. Like the related cognate terms 'wealth' and 'welfare', economics sources 
may contrast the state with its opposite. The study of well-being is divided into subjective wellbeing and objective well-being.

Well-being can be understood as how people feel and how they function, both on a personal and a social level, and how they evaluate their lives as a whole. To break this down, how people feel refers to emotions such as happiness or anxiety. How people function refers to things such as their sense of competence or their sense of being connected to those around them. How people evaluate their life as a whole is captured in their satisfaction with their lives, or how they rate their lives in comparison with the best possible life. You can think of someone as having high well-being if they function well, have positive feelings day-to-day and overall and think their lives are going well; we call this 'flourishing'. Similarly, you can think of someone as having low well-being if they do not function well and have negative feelings day-to-day and overall.

Well-being is a much broader concept than moment-to-moment happiness: it includes happiness but also other things such as how satisfied people are with their lives as a whole, and things such as autonomy (having a sense of control over your life), purpose (having a sense of purpose in life). Some research reported that spiritual well-being was positively related to family support and social Support, but negatively related to loneliness (Jang \& Kim, 2003; Lee, 2002; Lee, 2003). However, spirituality should be investigated from a family perspective because the family becomes a key to the experience and practice of spirituality as well as the major source of care and support to enhance elders' health and well-being (WHO, 2000; Wright, 2005)

According to Erickson and kivnick (1986), late adulthood is a development period of life span where significant physical, cognitive, social and psychological changes take place. Various adjustment need to be made by the elderly in relation to retirement, deteriorating physical health, acceptance of death and often loneliness due to death of spouse and lack of social support. Loneliness occurs throughout the life course but increase with age. By the end of this decade, the population of older persons in India will be 100 million. But even then there has been little headway in setting up a separate bureau of older persons. The perceptions of older peoples situation should not be and is not generally or inevitably problematic, but some people face considerable insecurity and a lack of well being in old age.

\section{OBJECTIVES}

The objectives of the study are-

1. The main objective of the study to see the impact of spirituality on well-being among old age peoples.

2. To study the relationship between spirituality and different dimensions of well-being, i.e. Physical Well-being, Mental Well-being, Social Well-being, Emotional Well-being and Spiritual Well-being old age peoples.

3. To study the relationship between spirituality and over-all well-being among old age peoples. 


\section{HYPOTHESIS}

1. There will be a significant influence of spirituality on Well-being among old age people.

2. There will be relationship between spirituality and different dimensions of well-being, i.e. Physical, Mental, Social, Emotional and Spiritual Well-being old age peoples.

3. There will be significant correlation between spirituality as well as Well-being of old age peoples.

\section{METHOD}

\section{Sample}

The study was conducted on 100 old age peoples between the ages of 50 to 65 years. Sample was randomly selected from different areas of Aligarh. Most of the people experienced Spirituality is positively related to well being it effects positive on individual life mostly in old age peoples become more spiritual through which their Well-being become more healthy and good.

\section{Measures}

Spirituality Attitude Scale: developed by Hussain et al (2011) it comprises of 31 items. It is five point scale having alternatives give (5) strongly agree, (4) Disagree, (3) Neutral, (2) Agree, (1) strongly agree. But in negative items we reverse the scoring. It has two dimensions namely sense of purposeness and maintenance of discipline.

Well-being Scale: This Scale was developed by Jagsharanbir Sing and Dr. Asha Gupta, (2001). It consisted of five sub-scale namely-Physical Well-being, Mental Well-being, Social Wellbeing, Emotional Well-being and Spiritual Well-being. Each sub-scale has ten items and there are 50 items in total. Scores on all the sub-scale are added up to get a composite score as total well being. Minimum and maximum score can be 50 and 250 respectively. Only 10-15 minutes are required to administer the well being scale. It consist 29 positive items and 21 negative items. Reliability: Test-retest reliability of the scale was 0.98 and split half reliability was found 0.96 . Validity: Content and concurrent validity of the Well being Scale was established. Concurrent validity of the scores of well being scale was determined by comparing it with the scores of Subjective Well-being Inventory Sall and Nagpal (1992). Correlation between subjective well being inventory and physical well being, subjective well being inventory and social well being, subjective well being inventory and emotional well being, subjective well being inventory and spiritual well being and subjective well being and total well being were $-0.45,0.87,-0.90,0.28$, 0.18 and 0.53 respectively. 


\section{Procedure:}

A good rapport was establish with the old age people before we asked them to fill the questionnaires and care was taken to remove any misconceptions regarding the proposed study. Subjects were assured that the information gathered from them would be kept secret and were requested to extend their co-operation. The questionnaires were distributed to the subjects. The questionnaires were explained to the subjects by the investigator and the subjects were instructed to read the questionnaires carefully and if there is something vague in the written material, they were asked to make it clearly by asking the investigator. The subjects were then asked to complete the questionnaires. Subjects took half an hours to complete the questionnaires. After completing the questionnaires the subjects were asked to return their questionnaire to the investigator for further analysis.

\section{Statistical analysis:}

Analysis of the data is done according to the aim and objective of the study. Simple Linear Regression was applied to examine the Correlation between Spirituality and Well-being as well as Coefficient of Spirituality on Well-being.

\section{RESULTS}

Table-1: Represents Simple Linear Regression analysis, Spirituality as predictor of Wellbeing among Old age People.

Model Summary

\begin{tabular}{|l|r|r|r|r|}
\hline Model & \multicolumn{1}{|c|}{$\mathrm{R}$} & R Square & \multicolumn{1}{c|}{$\begin{array}{c}\text { Adjusted R } \\
\text { Square }\end{array}$} & $\begin{array}{l}\text { Change Statistics } \\
\text { R Square Change }\end{array}$ \\
\hline 1 & $.359^{\mathrm{a}}$ & .129 & .120 & .129 \\
\hline
\end{tabular}

a. Predictors: (Constant), Spirituality Overall

Table.1 represents the Model Summary indicating one Predictor of the model, in which correlation between Spirituality and Well-being was found to be $\mathrm{R}=.359$ which is significant, further R Square Change =.129 which represents the actual contribution of Spirituality to Wellbeing, the real covariance magnitude of Predictor variable which contribute to the Criterion Variable came out as $12.9 \%$. 
Table-2: Showing the Coefficient details of Spirituality and Well-being among Old age People.

\begin{tabular}{|c|c|c|c|c|c|c|}
\hline \multicolumn{7}{|c|}{ Coefficients ${ }^{\mathrm{a}}$} \\
\hline \multirow{2}{*}{\multicolumn{2}{|c|}{ Model }} & \multicolumn{2}{|c|}{$\begin{array}{c}\text { Unstandardized } \\
\text { Coefficients }\end{array}$} & \multirow{2}{*}{$\begin{array}{c}\begin{array}{c}\text { Standardized } \\
\text { Coefficients }\end{array} \\
\text { Beta }\end{array}$} & \multirow[b]{2}{*}{$\mathrm{t}$} & \multirow[b]{2}{*}{ Sig. } \\
\hline & & B & Std. Error & & & \\
\hline 1 & (Constant) & 115.549 & 8.365 & & 13.813 & .000 \\
\hline & $\begin{array}{l}\text { Spirituality } \\
\text { Overall }\end{array}$ & .565 & .148 & .359 & 3.813 & .000 \\
\hline
\end{tabular}

Table-2 (Coefficient) indicates that Spirituality (Predictor) influences Well-being (WB) (Criterion). The Statistical value given in the mentioned table indicates that $\mathrm{t}=3.813$ values are significant for Spirituality and also show the positive relationship between Spirituality and WB. The Value of Partial Correlation is $r=.359$ which indicates that Spirituality significantly influences degree of WB among Old age People.

Table-3: Showing the Correlations between Spirituality and different dimensions of Wellbeing among Old age People.

Correlations $^{\mathbf{a}}$

\begin{tabular}{|ll|r|r|r|r|r|}
\hline & \multicolumn{1}{|c|}{$\begin{array}{c}\text { Physical } \\
\text { Well-being }\end{array}$} & $\begin{array}{c}\text { Mental } \\
\text { Well-being }\end{array}$ & $\begin{array}{c}\text { Social } \\
\text { Well-being }\end{array}$ & $\begin{array}{c}\text { Emotional } \\
\text { Well-being }\end{array}$ & $\begin{array}{c}\text { Spiritual } \\
\text { Well-being }\end{array}$ \\
\hline $\begin{array}{l}\text { Spirituality } \\
\text { Overall }\end{array}$ & $\begin{array}{l}\text { Pearson } \\
\text { Correlation }\end{array}$ & $.542^{* * *}$ & $.592^{* *}$ & $.524^{* * *}$ & $.527^{* * *}$ & $.451^{* * *}$ \\
& & & & & & \\
& $\mathrm{~N}$ & 100 & 100 & 100 & 100 & 100 \\
\hline
\end{tabular}

**. Correlation is significant at the 0.01 level (2-tailed).

Table-3 represents the Correlations between Overall Spirituality and different dimensions of Well-being, which shows that Physical, Mental, Social and Emotional; Spiritual Well-beings are significantly correlated with Spirituality. 
Table-4: Showing the Correlations between Well-being and different dimensions of Spirituality among Old age People.

Correlations

\begin{tabular}{|rr|r|r|}
\hline & & \multicolumn{1}{c|}{$\begin{array}{c}\text { Sense Of } \\
\text { Purposeness }\end{array}$} & $\begin{array}{c}\text { Maintenance } \\
\text { Of Discipline }\end{array}$ \\
\hline Overall Well-being & Pearson Correlation & $.696^{* *}$ & $.534^{* * *}$ \\
& & & \\
& $\mathrm{~N}$ & 100 & 100 \\
\hline
\end{tabular}

**. Correlation is significant at the 0.01 level (2-tailed).

Table.4 shows the positive and significant correlation between Well-being Overall and the different dimensions of Spirituality i.e. Sense of Purposeness as well as Maintenance of discipline among Old age people.

\section{DISCUSSION}

In our findings the statistical analysis we use analyses of regression and parsons' product moment coefficient of correlation were workout between spirituality and its two dimensions sense of Purposeness and maintenance of discipline with well-being and its five dimensions that Physical, Mental, Social and Emotional and Spiritual Well-beings. The analysis was done using SPSS version 16.0. Table.1 represents the Model Summary indicating one Predictor of the model, in which correlation between Spirituality and Well-being was found to be $\mathrm{R}=.359$ which is significant, further $\mathrm{R}$ Square Change $=.129$ which represents the actual contribution of Spirituality to Well-being, the real covariance magnitude of Predictor variable which contribute to the Criterion Variable came out as $12.9 \%$. This finding supported by a number of studies It has been found to be particularly important among older adults, and positively linked to selfappraised good health among elders (Daaleman and Frey, 2004). Table-2 (Coefficient) indicates that Spirituality (Predictor) influences Well-being (WB) (Criterion). The Statistical value given in the mentioned table indicates that $\mathrm{t}=3.813$ values are significant for Spirituality and also show the positive relationship between Spirituality and WB. The Value of Partial Correlation is $r=.359$ which indicates that Spirituality significantly influences degree of WB among Old age People. The relationships between these two variables represent linear correlation; it means that when Spirituality increases WB also increases and when Spirituality decreases then WB also decreases. This finding supported by a number of studies Spirituality and religion have positive associations with well-being, general psychological function, and marital satisfaction, and negative associations with suicide, delinquency, criminal behaviors, and drug/alcohol use. Especially, sense of hope and peace, love and joy, meaning and purpose in life, selftranscendence, forgiveness of self and others, awareness and acceptance of hardship and 
mortality, and a heightened sense of physical and emotional well-being have been indicated as consequences of spirituality in nursing literature (Haase et al., 1992; Reed, 1986; Tanyi, 2002). Table-3 represents the Correlations between Overall Spirituality and different dimensions of Well-being, which shows that Physical, Mental, Social and Emotional; Spiritual Well-beings are significantly correlated with Spirituality. Table.4 shows the positive and significant correlation between Well-being Overall and the different dimensions of Spirituality i.e. Sense of Purposeness as well as Maintenance of discipline among Old age people. There is a positive relationship between spirituality and well-being. Spirituality is associated deep values, and inner resources of the older person. This investigation suggest that spirituality grows through continual mutual process when individuals make choices to actualize potentials which reflect a sense of meaning in life, interconnectedness with all living things, and awareness of transcendent dimension of being. This search shows that spirituality plays an important role in the well-being of older people.

\section{CONCLUSION}

The above findings have proved that Spirituality has favorable impact and relationship with wellbeing among old age people. Spiritual people have a good well-being and they are well adjusted in the society. It was also found that spirituality enhance the well-being. Hence, to maintain healthy life spirituality is necessary. Spirituality plays an important role in Indian society across all ages. As one gets older, the role of spirituality becomes more prominent. Elderly persons with a high spirituality were able to manage their well-being better. People usually when they get old, they lose the desires of the proper man in our life such as sex, popularity and success, so they get too close to God because whoever leaves his desires and precede his life is better and closer to God.

\section{REFERENCES}

1. As in Journal of Economic Literature Health, education, and welfare JEL: I Subcategories at JEL: I3 - Welfare and Poverty.

2. Dalby P: Is there a process of spiritual change or development associated with ageing? A critical review of research. Aging Ment. Health 10, 4-12 (2006).

3. Diener, E., Suh, E. M., Lucas, R. E. \& Smith, H. L. (1999). Subjective well-being: Three Decade of progress. Psychological Bulletin, 125(2):276-302

4. Jang, E. \& Kim, S. (2003). Study on spiritual well-being of elderly people in the community. Journal of Korean gerontological nursing, 5(2):193-204.

5. King, Y. \& Seidlitz, L. (2013). Religion, Spirituality and mental health:results from a national study of English households. Journal of psychiatry, 202(1), 68-73.

6. Koenig HG, McCullough ME, Larson DB: Handbook of Religion and Health. Oxford University Press, NY, USA (2001). 
7. Koenig HG: Research on religion and aging: an annotated bibliography. Westport CT (Ed.). Greenwood Press, Buckinghamshire, UK (1995).

8. Lee, M. K. (2002). Relationship between Perceived Family Support and Spiritual WellBeing in Elderly. Master Thesis, Yonsei University, Korea.

9. Lee, S. (2003). The Relationship of Spiritual Well-Being, Loneliness and Life Satisfaction Of the Elderly in Local Church. Master Thesis, Kosin University, Korea.

10. Miller, W.R.and Thorenson, C.e. (2000) spirituality and health. In miller, W.R. (Ed.) integrating spirituality into treatment, Washington, D.C.: American Psychological Association, 3-18.

11. Moberg DO: Research in spirituality, religion and aging. J. Gerontol. Soc. Work 45, 1140 (2005).

12. Moberg DO: Aging and Spirituality: Spiritual Dimensions of Aging Theory, Research, Practice, and Policy. The Haworth Pastoral Press. Binghamton, NY, USA (2006).

13. Reed, P. G. (1992). An emerging paradigm for the investigation of spirituality in nursing. Research in Nursing and Health. 15:349-347.

14. Swinton, J. (2001). Spirituality and Mental health care: Rediscovering a 'forgotten' dimension. Jessica Kingsley Publishers; London and Philadelphia

15. Swinton, J. (2001). Spirituality and Mental health care: Rediscovering a 'forgotten' Dimension. Jessica Kingsley Publishers; London and Philadelphia

16. Tanyi, R. A. (2002). Towards clarification of the meaning of spirituality. Journal of Advanced Nursing, 39(5):500-509

17. Wright, L. M. (2005). Spirituality, Suffering and Illness: Ideas for healing. Lisa B.Deitch.

18. WHO Regional Office for the Western Pacific (2000, June 26) Social Development and Ageing: Crisis or Opportunity. Retrieved November, 9, 2006 from http://www.who.int/ageing/publications/development/alc_social_development.pdf

19. Wullf, D.M. (1996). The psychology of religion: an overview. In E.P. Shapraspe (Ed.) Religion and clinical practice of psychology, Washington, D.C.: American psychological association, pp.43-70.

20. Daaleman TP, Frey BB. (2004). The spirituality index of well-being: A new instrument for health-related quality of life. Annals of Family Medicine, 2:499-503.

21. Haase, J.E., Britt, T., Coward, D.D., Keidy, N.K., \& Penn, P.E. (1992). Simultaneous concept analysis of spiritual perspective, hope, acceptance and self-transcendence. Image: Journal of Nursing Scholarship, 24, (2), 141-147.

22. Reed, P.G. (1986). Developmental resources and depression in the elderly. Nursing Research, 35(6), 368-374.

23. Tanyi, R.A. (2002). Towards clarification of the meaning of spirituality. Journal of Advanced Nursing, 39, (5), 500-509. 